\title{
气候变化和人类活动对鄱阳湖流域径流过程影响的定量分析”
}

\author{
刘剑宇 ${ }^{1,2}$, 张 强 ${ }^{1,2,3}$ *** $^{\text {, 邓晓宇 }}{ }^{1,2}$, 慈 晖 ${ }^{1,2}$, 陈晓宏 ${ }^{1,2,3}$ \\ (1: 中山大学水资源与环境系,广州 510275) \\ (2: 中山大学华南地区水循环与水安全广东省普通高校重点实验室,广州 510275) \\ (3: 中山大学广东省城市化与地理环境空间模拟重点实验室,广州 510275)
}

\begin{abstract}
摘 要: 量化气候变化和人类活动对流域水文影响及其对流域水资源规划和管理具有重要的理论与现实意义. 采用水 文模型和多元回归法定量分析气候变化和人类活动对鄱阳湖 “五河”径流的影响,并通过与灵敏度分析法对比来进一步 验证分析结果. 研究表明, 1970-2009 年,气候变化和人类活动对鄱阳湖流域径流增加的贡献率分别为 $73 \%$ 和 $27 \%$. 气 候变化是饶河、信江和赣江径流增加的主导因素, 而人类活动是修水径流增加的主要因素, 是抚河径流减少的主要原因. 另外, 不同季节影响径流变化的主导因素又有不同, 人类活动为干季(11 月到次年 2 月)径流增加和湿季 (4-6月)径流 减小的主导因素, 其贡献率分别为 $78.9 \%$ 和 $82.7 \%$. 本研究可为鄱阳湖流域防洪抗旱及水资源优化配置提供重要科学 依据.
\end{abstract}

关键词: 鄱阳湖流域;气候变化; 人类活动;径流;水文模型;不同时间尺度

\section{Quantitative analysis the influences of climate change and human activities on hydrological processes in Poyang Basin}

\author{
LIU Jianyu ${ }^{1,2}$, ZHANG Qiang ${ }^{1,2,3 * *}$, DENG Xiaoyu ${ }^{1,2}$, CI Hui ${ }^{1,2}$ \& CHEN Xiaohong ${ }^{1,2,3}$ \\ (1: Department of Water Resources and Environment, Sun Yat-sen University, Guangzhou 510275, P.R.China) \\ (2: Key Laboratory of Water Cycle and Water Security in Southern China of Guangdong High Education Institute, Sun Yat-sen \\ University, Guangzhou 510275, P.R.China) \\ (3: School of Geography and Planning, Guangdong Key Laboratory for Urbanization and Geo-simulation, Sun Yat-sen Univer- \\ sity, Guangzhou 510275, P.R.China)
}

\begin{abstract}
The streamflow processes of the Poyang Basin are significantly altered due to combined influences from climate changes and human activities, which further triggers higher occurrence frequency of floods and droughts and hence serious water resources problems. In this sense, quantitative evaluations of influences from human activities and climate changes respectively are of greatly theoretical and practical merits in terms of planning and management of water resources. In this study, hydrological models and multivariate regression technique are used to identify quantitatively impacts of climate changes and human activities on streamflow variations of five tributaries of the Poyang Basin. Furthermore, the results are further corroborated by comparisons between the analyses by hydrological models and multivariate regression methods and also sensitivity analysis technique. The explained variables of the multivariate models are done using the adjustment coefficients with different explained variables, showing that the multiple regression models are the right ones with evaporation and the precipitation of the last month. The NASH coefficient for the AWBM model is larger than 0.842 , being better than the modeling results by the multivariate regression models. Meanwhile the impacts modeled by the above-mentioned techniques are similar, and are good for identification of the impacts of human activities and climate changes on streamflow variations. It should be noted here that the sensitivity method cannot exclude the base-period human influences. Due to increase of streamflow as a result of human interferences, the influence component by climate changes is usually exaggerat-
\end{abstract}

* 国家杰出青年基金项目(51425903)、鄱阳湖湿地与流域研究教育部重点实验室(江西师范大学)主任开放基金项 目 (ZK2013006) 和香港特别行政区研究资助局项目 (CUHK441313) 联合资助. 2015-04-01 收稿; 2015-06-30 收修改稿. 刘剑宇(1991 ), 男, 博士研究生;E-mail: liujianyu68@163.com.

** 通信作者;E-mail: zhangq68@ mail.sysu.edu.cn. 
ed. Analysis of this study indicates that precipitation, potential evaporation and also human activities have the potential to increase the streamflow of the Poyang Basin and the fractional contribution is $27 \%$ and $73 \%$, respectively. Climate changes can increase the streamflow of these five rivers considered in this study. Human activities increase the streamflow of the rivers except Fu River basin. In the Fu River basin, the streamflow decreases due to massive agricultural irrigation. Different influences can be identified for climate changes and human activities on tributaries of the Poyang Basin. Climate change is the major driving factor for the increase of the streamflow within the Rao, Xin and Gan River basins; however, human activity is the principle driving factor behind the increase of the streamflow of the Xiu River basin and also the decrease of the streamflow of Fu River basin. Meanwhile, different impacts of human activities and climate changes on streamflow variations are distinctly different on various temporal scales. On the annual time scale, increase of streamflow is large due to climate changes and human activities during $1970 \mathrm{~s}-1990 \mathrm{~s}$ and decrease of streamflow during 2000s. On the seasonal scale, human activities can well increase streamflow during dry season (December to February of the subsequent year) and decrease streamflow during wet season (April to June) with the fractional contribution of 78. $9 \%$ and $82.7 \%$ respectively. On the monthly scale, different influences of climate changes and human activities can be detected. Climate change is the main factor for the decrease of streamflow during May to June and human activities for the decrease of streamflow during February to May. The results of this study can provide theoretical ground for basin-scale water resources management under the influences of climate changes and human activities.

Keywords: Poyang Basin; climate changes; human activities; runoff; hydrological models; different time scales

气候变化和人类活动是影响流域水文情势的主要因素 ${ }^{[1]}$. 气候变化导致降水时空变化 ${ }^{[2]}$,进而影响径 流过程的时空变化, 而湖泊围殶、森林破坏、引水灌溉等人类活动改变了水资源时空分布特征 ${ }^{[3]}$. 随着水资 源短缺问题日益严峻及水旱灾害频发,在变化环境下探讨水循环要素的演变规律、定量分析气候变化和人 类活动对流域水循环过程的影响具有重要意义. 目前量化气候变化和人类活动对径流影响的方法主要有 三种: 回归分析 ${ }^{[4-5]}$ 、灵敏度分析 ${ }^{[6-7]}$ 、水文模型模拟 ${ }^{[6,8]}$. 其中灵敏度分析法使用最为广泛,然而 Wang 等 $^{[9]}$ 通过概述量化气候变化和人类活动水文影响的主要方法, 指出灵敏度分析法无法消除基准期的人类活动影 响,所量化的气候变化影响量包含有基准期的人类活动影响量, 从而使气候变化影响量存在较大偏差. 鉴 于此, 本文采用回归分析与水文模型相结合的思路, 量化气候变化和人类活动对鄱阳湖流域径流的影响, 将 所求结果与灵敏度分析法下气候变化与人类活动影响量相比较, 以实例进一步分析并验证 $\mathrm{Wang}^{\text {等 }}{ }^{[9]}$ 的推 论. 气候变化和人类活动的水文响应在不同时间尺度上存在一定差异 ${ }^{[10]}$, 大部分研究 ${ }^{[4-8]}$ 都以年尺度来评 估影响量, 而对季节和月尺度上的研究较少. 年尺度影响量分析可以得到不同时期气候变化和人类活动的 水文效应, 而季节和月尺度影响量分析对年内水资源合理配置具有重要意义, 例如在季节性干旱频发区域 的农业灌溉和工业用水方面. 因此, 季节或月尺度下气候变化与人类活动对径流的影响值得进一步研究.

鄱阳湖流域面积 $16.22 \times 10^{4} \mathrm{~km}^{2}$, 是我国最大的淡水湖泊, 也是我国十大生态功能保护区之一, 对维系 区域和国家生态安全具有重要意义. 近年来湖区及流域内水旱灾害频繁, 特别是 1900s 和 2000s. 水旱灾害 频发使湖区生态环境及整个流域的水资源管理得到更多关注.气候变化对鄱阳流域径流变化影响显著,人 类活动主要通过改变下垫面状况间接导致径流发生变化 ${ }^{[11]}$. 田鹏等 ${ }^{[12]}$ 采用 SWAT 模型, 探讨土地利用与气 候变化对径流变化的贡献率. 邓晓宇等 ${ }^{[13]}$ 采用 HSPF 水文模型, 量化气候变化和对信江流域径流变化影响. $\mathrm{Ye}$ 等 ${ }^{[7]}$ 采用灵敏度分析法, 区分气候变化和人类活动对鄱阳湖流域赣江、信江、抚河径流的影响. 已有的研 究采用单一的量化方法探讨气候变化和人类活动对鄱阳湖流域径流过程的影响, 没有对不同类型量化方法 的对比研究. 同时, 已有的研究均以年或者年代为研究尺度, 没有考虑季节和月尺度上气候变化和人类活 动对径流影响量的差别. 另外, 过去的研究针对的是鄱阳湖流域部分河段或河流, 尚未有对整个鄱阳湖流 域 “五河” 径流系统研究的相关成果. 因此, 本文通过对比多元线性回归法、灵敏度分析法和水文模型 3 种 不同类型的量化方法, 旨在探讨年、季节和月的不同时间尺度下,气候变化和人类活动对鄱阳湖流域“五河” 径流变化的影响. 该研究有助于理解气候变化和人类活动对鄱阳湖流域径流量增加的具体影响, 对区域水 资源合理配置和管理具有重要意义.

\section{1 研究区域和数据}

鄱阳湖流域气候类型属于亚热带季风气候, 降水年内分配不均, 流域内大部分地区 4-6月降水量占多 
年平均降水量的 45\% 50\%, 而 7-9 月降水量小于蒸发量 ${ }^{[14]}$. 鄱阳湖属季节性洪泛湖泊, 水位变化非常明 显, 水位年变幅在 $2.25 \sim 12.18 \mathrm{~m}$ 之间 ${ }^{[15]}$.

本文所用水文数据为万家埠、虎山、李家渡、梅港和外洲 5 个水文站 1955-2009 年日流量资料,其中万 家埠水文站在修水的主要支流潦河之上, 万家埠水文站之上没有大中型水库分布, 因此结合其它站点可以 很好地研究大型水库对径流变化的影响. 水文数据来自江西省水文局. 气象数据为鄱阳湖流域及其周边 31 个气象站 1955-2009 年逐日气象资料(图 1). 潜在蒸发量采用 Penman-Monteith ${ }^{[16]}$ 公式计算, 考虑到流 域内气象站分布不均,全流域及各子流域面降水量和潜在蒸发量均采用泰森多边形法计算.

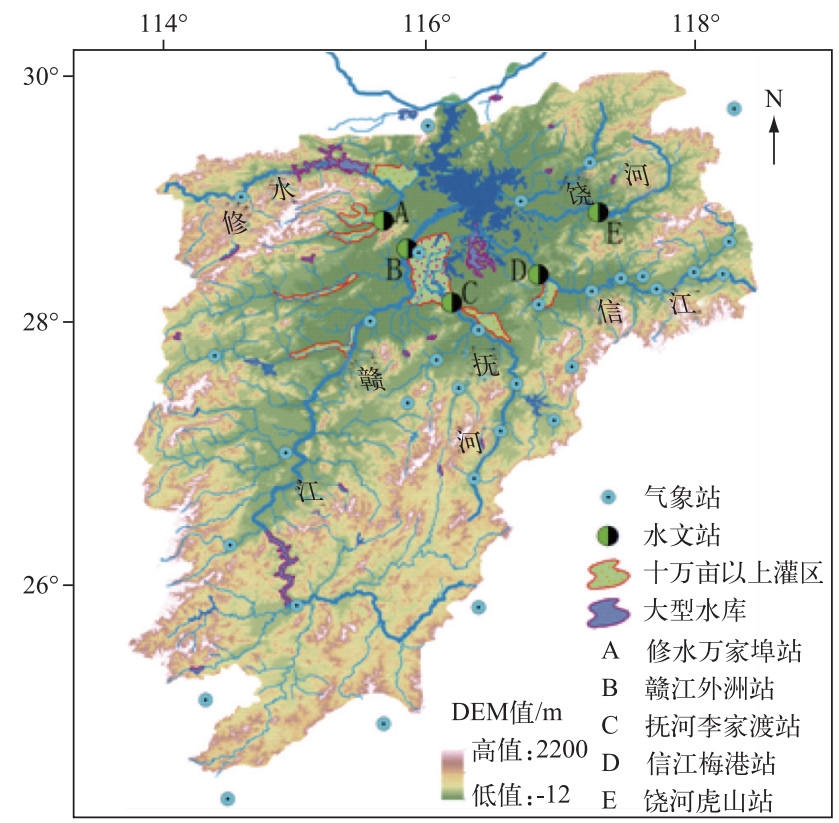

图 1 鄱阳湖流域、主要水文站点、水库、灌区位置

Fig.1 Location of the hydrological stations, water reservoirs and irrigation areas in Poyang Basin

\section{2 研究方法}

\section{1 趋势检验方法}

采用 Mann-Kendall 趋势检验法(下文简称 M-K 检验)、Sen 坡度估计法 ${ }^{[17]}$ 和线性回归方法进行趋势分 析. M-K 检验方法介绍较多 ${ }^{[6-8]}$, 这里不再赘述. 确定了序列变化趋势后, 采用 Sen 坡度估计法计算变化趋 势大小. 序列自相关性对趋势检验产生较大影响, Yue 等 ${ }^{[18]}$ 对预白化方法 ${ }^{[19]}$ 进行改进, 提出趋势自由预白 化方法 (TFPW). 对于自相关系数达到 0.05 显著性水平的序列,采用自由预白化方法去除序列自相关.

\section{2 定量区分方法}

径流的变化总量为影响期与基准期径流量的差值,用公式表示为:

$$
\Delta Q_{\mathrm{tot}}=Q_{\mathrm{obs} 2}-Q_{\mathrm{obs} 1}
$$

式中, $Q_{\mathrm{obs} 2}$ 为影响期径流量, $Q_{\mathrm{obs} 1}$ 为基准期径流量, $\Delta Q_{\text {tot }}$ 为影响期相对基准期径流的变化量. 径流变化由 气候变化与人类活动引起 ${ }^{[9]}$. 因此, 径流变化量又可表示为:

$$
\Delta Q_{\text {tot }}=\Delta Q_{\text {clim }}+\Delta Q_{\text {hum }}
$$

式中, $\Delta Q_{\mathrm{hum}}$ 和 $\Delta Q_{\mathrm{clim}}$ 分别为径流变化量中的人类活动和气候变化影响量. $Q_{\mathrm{obs} 1}$ 是基准期气候条件和人类活 动共同作用的结果. 通过基准期校准的模型得到影响期模拟径流 $Q_{\text {sim }}$, 主要受影响期气候变化影响, 同时 还包含基准期的人类活动影响. 而 $Q_{\mathrm{obs} 2}$ 是基准期的人类活动和影响期气候变化与人类活动三者共同影响 
所产生的径流量. 因此, $Q_{\text {sim }}$ 与 $Q_{\mathrm{obs} 1}$ 的差值即为气候变化影响量, $Q_{\mathrm{obs} 2}$ 与 $Q_{\mathrm{sim}}$ 之间的差值即为影响期新增 人类活动对径流的影响量. 用公式表示即:

$$
\begin{aligned}
& \Delta Q_{\text {clim }}=Q_{\text {sim }}-Q_{\text {obs } 1} \\
& \Delta Q_{\text {hum }}=Q_{\text {obs } 2}-Q_{\text {sim }}
\end{aligned}
$$

2.2.1 线性回归模型 Boughton 等 ${ }^{[20]}$ 研究指出, 加人叶面积指数、森林覆盖率、植物持水能力等流域特征要 素对改善径流回归效果没有明显帮助. 因此,本文回归分析中不考虑上述流域特征因素, 以基准期 (19551969 年) 月平均降水和潜在蒸发及上月月平均降水和潜在蒸发不同解释变量进行组合 (表 1 ), 分别对该时 期径流进行回归.

Miao 等 ${ }^{[5]}$ 采用一元线性回归法, 建立降水与径流、泥沙的线性关系, 初步量化人类活动与气候变化对黄 河水沙演变贡献率. Jiang 等 ${ }^{[4]}$ 则采用降水、潜在蒸发 2 个解释变量对径流进行回归,进而量化气候变化和 人类活动影响量. 从月尺度来看, 上月降水量、潜在蒸发量对当月产汇流可能存在较大影响, 但以上研究均 未考虑这一因素, 也未对降水、潜在蒸发及上月降水、潜在蒸发等不同解释变量选择, 对径流回归效果影响 的对比研究. 因此, 本文将分以下 4 种情况分别对径流回归效果进行研究探讨: (1) 只考虑降水的一元线性 回归; (2) 考虑降水和潜在蒸发的二元线性回归; (3) 考虑降水、潜在蒸发以及上月降水的三元线性回归; (4) 考虑降水、潜在蒸发, 以及上月降水、潜在蒸发的四元线性回归.

多元线性回归伴随解释变量的增加, 判定系数往往增大 ${ }^{[21]}$. 若采用传统方法对判定系数进行求算, 则 对比研究没有任何意义. 因此, 本文采用校正判定系数 ${ }^{[22]}$ 对不同数量解释变量下的回归模型进行比较, 以 期优选出基准期的最佳回归函数. 校正的判定系数可通过公式 (5)求得:

$$
R_{a}^{2}=1-\frac{S S E /(n-k-1)}{S S T /(n-1)}
$$

式中, $R_{a}^{2}$ 为校正判定系数, $S S E$ 为残差平方和 $\sum\left(Q_{i}-\hat{Q}_{i}\right)^{2}, S S T$ 为总离差平方和 $\sum\left(Q_{i}-\bar{Q}\right)^{2}, n-k-1 、 n-1$ 分别为误差平方和、总 体平方和的自由度. $Q_{i} 、 \hat{Q}_{i}$ 分别为 $i$ 月实测月径流量和月回归径 流量, $\bar{Q}$ 为多年平均月径流量.

2.2. 2 AWBM 模型 AWBM 模型 (Australia Water Balance Mod$\mathrm{el})^{[23]}$ 是一个基于水量平衡原理的集总式降水径流模型 . 模型 输人包括日降水量、日潜在蒸发量和日实测径流量 3 部分. AWBM 模型结构如图 2 所示. 该模型将流域分成 3 种不同的地 表水储蓄 $\mathrm{A} 1 、 \mathrm{~A} 2 、 \mathrm{~A} 3$, 其存储能力分别为 $\mathrm{C} 1 、 \mathrm{C} 2$ 和 $\mathrm{C} 3$. 不同地 表水储蓄之间相互独立, 但满足限制条件: $\mathrm{A} 1+\mathrm{A} 2+\mathrm{A} 3=1$.

在模型计算过程中,若地表水储蓄为负值,则将该值以 0 代

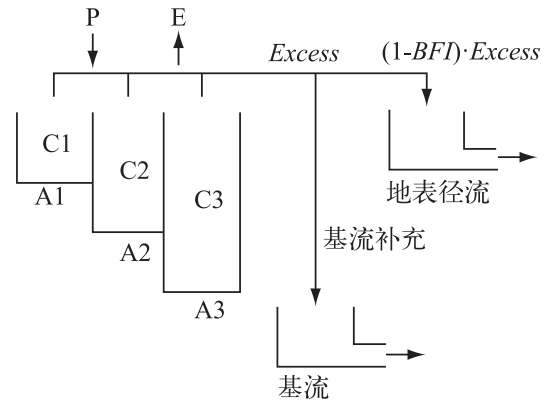

图 2 AWBM 结构框图 ${ }^{[23]}$ 替; 若地表水储蓄量超过其容量,则超过部分将根据基流指数转 化为地表径流储蓄与补充基流储蓄. 转化过程如下式所示:

$$
\begin{gathered}
\operatorname{Excess}(n, m)=\operatorname{Store}(n, m)-C(m) \\
S(n)=S(n-1)+\sum_{m=1}^{3}[(1-B F I) \cdot \operatorname{Excess}(n, m)] \\
B S(n)=B S(n-1)+\sum_{m=1}^{3}[B F I \cdot \operatorname{Excess}(n, m)]
\end{gathered}
$$

式中,Store $(n, m)$ 表示第 $m$ 个地表水储蓄在第 $n$ 个时段内的蓄水量, $C(m)$ 为第 $m$ 个地表水储存容量. $S(n)$ 、 $B S(n)$ 分别为时段 $n$ 内地表径流储蓄量、基流储蓄量; $B S$ 为基流储蓄量, $B F I$ 为基流指数. 地表径流和基流演 进按照一元线性水库出流量理论进行计算, 再线性叠加演进的地表径流和基流,得到时段内模拟径流量.

$$
\begin{gathered}
Q_{\mathrm{s}}(n)=\left(1-K_{\mathrm{S}}\right) \cdot S(n) \\
Q_{\mathrm{b}}(n)=(1-K) \cdot B S(n) \\
Q_{\mathrm{C}}(n)=Q_{\mathrm{s}}(n)+Q_{\mathrm{b}}(n)
\end{gathered}
$$


式中: $K$ 和 $K_{\mathrm{S}}$ 分别为基流和地表径流衰退系数; $Q_{\mathrm{s}}(n)$ 和 $Q_{\mathrm{b}}(n)$ 分别为地表径流和基流; $Q_{\mathrm{c}}(n)$ 为时段内计 算径流量. 模型优化方法采用 Genetic 算法进行参数率定及模型检验, 目标函数采用 NASH-Sutcliff 标准 $(N A S H)$ 表示.

\section{3 结果}

\section{1 趋势分析}

趋势分析结果 (表 1) 表明, “五河”流域年降水量均呈增加趋势, 但未达到 $95 \%$ 置信水平, 趋势不显著. “五河” 流域年潜在蒸发量减少趋势显著。修水、饶河、信江、贑江年径流量均呈显著增加趋势, 分别以 2. 922、1. $992 、 2.922$ 和 $2.144 \mathrm{~mm} / \mathrm{a}$ 的趋势增加. 相反, 抚河年径流量呈减小趋势, 以 $-0.723 \mathrm{~mm} / \mathrm{a}$ 的趋势 减少. 就全流域而言, 降水量以 $1.12 \mathrm{~mm} / \mathrm{a}$ 的趋势增加, 蒸发量以 $-0.69 \mathrm{~mm} / \mathrm{a}$ 的显著趋势减小, 全流域年 径流深( “五河” 年径流深加权) 以 $1.974 \mathrm{~mm} / \mathrm{a}$ 的显著趋势增加. 修水、饶河、信江、赣江年径流深增加趋势 值均大于降水量增加值与潜在蒸发量减小值之和. 以修水流域为例, 修水年降水量以 $0.647 \mathrm{~mm} / \mathrm{a}$ 的趋势 增加, 年蒸发量以 $0.731 \mathrm{~mm} / \mathrm{a}$ 的趋势减小, 而径流深以 $2.92 \mathrm{~mm} / \mathrm{a}$ 的趋势增加, 远大于降水量增加值与潜 在蒸发量减小值之和. 因此, 除降水量与潜在蒸发量之外, 人类活动总体增加了修水、饶河、信江和赣江流 域的年径流量. 抚河流域降水量增加最为明显, 潜在蒸发量减少趋势也超过全流域平均水平, 但该流域年 径流量变化趋势与其它“四河”相反,可见人类活动较大程度上减小了抚河年径流量.

上述分析表明, 径流量的变化不仅仅由降水量与潜在蒸发量变化所导致, 同时还受到人类活动的影响, 并且人类活动的影响有可能大于气候变化的影响. 另外, 人类活动对鄱阳湖流域各个子流域影响程度不 同,对径流量变化的影响方向也存在差异.

表 1 鄱阳湖流域降水、潜在蒸发、径流序列 M-K 检验及 Sen 坡度估计统计

Tab. 1 Summarized results of M-K test with Sen's slope for the series of precipitation, potential evaporation and runoff in Poyang Basin

\begin{tabular}{|c|c|c|c|c|c|c|c|}
\hline \multirow{2}{*}{ 流域 } & & \multicolumn{3}{|c|}{ M-K 检验 } & \multicolumn{3}{|c|}{ Sen 坡度估计 } \\
\hline & & tau & $p$ & 趋势 & $Q / \mathrm{mm}$ & $Q_{\text {lower }} / \mathrm{mm}$ & $Q_{\text {upper }} / \mathrm{mm}$ \\
\hline \multirow[t]{3}{*}{ 修水 } & $P$ & 0.011 & 0.692 & + & 0.647 & -3.131 & 4. 649 \\
\hline & PET & -0.086 & 0.001 & - & -0.731 & -1.339 & -0.135 \\
\hline & $\boldsymbol{R}$ & 0.118 & $<0.001$ & + & 2.922 & 1. 256 & 4. 800 \\
\hline \multirow[t]{3}{*}{ 饶河 } & $P$ & 0.014 & 0.605 & + & 0.730 & -3.438 & 4. 884 \\
\hline & PET & -0.101 & $<0.001$ & - & -0.904 & -1.495 & -0.292 \\
\hline & $\boldsymbol{R}$ & 0.089 & 0.001 & + & 1.992 & 0.489 & 3. 653 \\
\hline \multirow[t]{3}{*}{ 抚河 } & $P$ & 0.032 & 0.230 & + & 1.894 & -2.192 & 5.897 \\
\hline & PET & -0.098 & $<0.001$ & - & -0.830 & -1.491 & -0.251 \\
\hline & $R$ & -0.030 & 0.262 & - & -0.723 & -2.478 & 0.956 \\
\hline \multirow[t]{3}{*}{ 信江 } & $P$ & 0.010 & 0.698 & + & 0.731 & -3.943 & 5. 180 \\
\hline & PET & -0.115 & $<0.001$ & - & -1.017 & -1.644 & -0.397 \\
\hline & $R$ & 0.109 & $<0.001$ & + & 2.922 & 1. 096 & 4. 870 \\
\hline \multirow[t]{3}{*}{ 赣江 } & $P$ & 0.022 & 0.416 & + & 1.078 & -2.489 & 4. 655 \\
\hline & PET & -0.067 & 0.012 & - & -0.578 & -1.175 & 0.013 \\
\hline & $\boldsymbol{R}$ & 0.101 & $<0.001$ & + & 2. 144 & 0.685 & 3.653 \\
\hline \multirow[t]{3}{*}{ 全流域 } & $P$ & 0.023 & 0.401 & + & 1. 118 & -2.581 & 4. 762 \\
\hline & PET & -0.083 & 0.002 & - & -0.690 & -1.302 & -0.114 \\
\hline & $R$ & 0.090 & 0.001 & + & 1. 974 & 0.406 & 3. 652 \\
\hline
\end{tabular}

$* P$ 表示月平均降雨量, $P E T$ 表示月平均潜在蒸发量, $R$ 表示径流深; $t a u$ 为 Kendall 等级相关系数, $p$ 为显著性水平; + 为 增加趋势, - 为减少趋势; $Q$ 和 $Q_{\text {lower }} 、 Q_{\text {upper }}$ 分别表示坡度变化值和坡度的 $95 \%$ 置信区间最低、最高值; 字体加黑表示趋势 在 $95 \%$ 置信区间内显著. 


\section{2 模型率定}

量化气候变化和人类活动对径流影响的相关研究 ${ }^{[5-8]}$, 大部分以径流序列变异点作为基准期和影响期 的分界点, 并认为变异前径流序列为人类活动可以忽略不计的 “天然期”. 刘剑宇等 ${ }^{[24]}$ 研究表明鄱阳湖流域 修水、饶河、信江、赣江径流序列变异点均由气候变化所导致, 抚河径流序列无明显变异点, 故采用变异点为 基准期和实测期的分界点已无实际意义. 另外, 本文以 $Q_{\mathrm{obs} 2}$ 与 $Q_{\mathrm{sim}}$ 的差值为气候变化影响量, 同时以 $Q_{\mathrm{sim}}$ 与 $Q_{\text {obs } 1}$ 的差值为人类活动影响量, 这种方式能很好地消除或消减基准期的人类活动影响. 因此, 本文采用序列 前 15 年(1955-1969 年) 为基准期,而序列后 40 年(1970-2009 年) 为影响期.

3. 2.1 线性回归 径流回归中不同的解释变量组合下, 校正决定系数 $\left(R_{\mathrm{a}}^{2}\right)$ 存在较大差异 (表 2). “五河” 及 全流域单一的降水径流回归决定系数平均值为 0.786 ; 加人潜在蒸发变量后, 决定系数提高幅度不明显. 再 加人上月降水变量后, 回归效果明显改善, 校正的决定系数均在 0.810 以上, 其中信江的回归效果最好, 达 到 0.905. 又加人上月蒸发变量后, “五河” 及全流域调整的决定系数几乎没有变化甚至略微减小, 而除饶河 外, 其它 “四河” 多元回归方程的上月潜在蒸发变量回归系数均为正, 与蒸发作用减少径流的实际情况不符, 故多元回归中不能加人上月潜在蒸发这一解释变量. 因此, 考虑降水、蒸发及上月降水量 3 个解释变量的三 元线性回归模式为最佳选择.

表 2 不同解释变量下月径流量回归方程校正决定系数*

Tab. 2 The adjust determination coefficients for multiple linear regressions by different explanatory variables

\begin{tabular}{|c|c|c|c|c|c|c|}
\hline 解释变量 & 修水 & 饶河 & 抚河 & 信江 & 赣江 & 全流域 \\
\hline$P$ & 0.752 & 0.776 & 0.782 & 0.878 & 0.733 & 0.794 \\
\hline$P+P E T$ & 0.765 & 0.783 & 0.782 & 0.882 & 0.743 & 0.801 \\
\hline$P+P E T+P^{\prime}$ & 0.810 & 0.819 & 0.833 & 0.905 & 0.831 & 0.865 \\
\hline$P+P E T+P^{\prime}+P E T^{\prime}$ & 0.813 & 0.818 & 0.834 & 0.906 & 0.831 & 0.865 \\
\hline
\end{tabular}

* $P^{\prime} 、 P E T^{\prime}$ 分别表示上个月月平均降雨量、潜在蒸发量.

以基准期“五河” 及全流域月平均降雨量 $(P)$ 、月平均蒸发量 $(E)$ 及上月平均降雨量 $\left(P^{\prime}\right)$ 为解释变量, 分别对相应流域月平均流量 $(Q)$ 进行回归, 回归方程见表 3, 各回归方程决定系数 $R^{2}$ 均大于 $0.810, F$ 统计值 在 248 以上, $F$ 统计值对应的 $P$ 值均小于 0.01 , 回归效果显著, “五河” 及全流域的多元回归模型均成立.

表 3 鄱阳湖流域基准期月径流序列最佳回归方程

Tab. 3 Optimal multiple linear regressions for the series of monthly runoff during baseline period in Poyang Basin

\begin{tabular}{lcccc}
\hline 流域 & 回归方程 & $R^{2}$ & $F$ 统计值 & 显著性水平 \\
\hline 修水 & $Q=0.715 P+0.168 P^{\prime}-0.009 E-0.949$ & 0.810 & 248 & $P<0.0001$ \\
饶河 & $Q=0.697 P+0.221 P^{\prime}-0.100 E-1.114$ & 0.819 & 314 & $P<0.0001$ \\
抚河 & $Q=0.564 P+0.209 P^{\prime}-0.054 E-0.619$ & 0.834 & 340 & $P<0.0001$ \\
信江 & $Q=0.715 P+0.168 P^{\prime}-0.100 E-1.000$ & 0.906 & 473 & $P<0.0001$ \\
赣江 & $Q=0.445 P+0.274 P^{\prime}-0.169 E-0.340$ & 0.832 & 279 & $P<0.0001$ \\
全流域 & $Q=0.533 P+0.209 P^{\prime}-0.235 E-0.570$ & 0.866 & 369 & $P<0.0001$ \\
\hline
\end{tabular}

3.2. 2 AWBM 模型 以基准期 (1955-1969 年) 来校正模型, 其中 1955-1964 年为模型校准期, 1965-1969 年为模型验证期. 从图 3 可以看出, “五河” 及全流域模拟月平均径流深与实测月平均径流深拟合效果良好.

“五河”及全流域校准期与验证期的 $N A S H$ 系数见表 4. “五河” 校准期模拟 $N A S H$ 系数在 $0.840 \sim 0.977$ 之间, 验证期 $N A S H$ 系数 $0.927 \sim 0.977$ 之间. Moriasi 等 ${ }^{[25]}$ 的研究表明, $N A S H$ 系数大于 0.75 即表示模型模 拟效果良好, AWBM 模型适用于鄱阳湖流域径流模拟,运用 AWBM 模型对影响期地表径流模拟的可信度 较高. 
表 4 AWBM 模型校准期与验证期 $N A S H$ 系数

Tab. 4 NASH coefficient for AWBM during calibration and validation period

\begin{tabular}{lcccccc}
\hline 时期 & 竷江 & 信江 & 饶河 & 修水 & 抗河 & 全流域 \\
\hline 校准期 & 0.936 & 0.940 & 0.977 & 0.842 & 0.963 & 0.959 \\
验证期 & 0.979 & 0.932 & 0.977 & 0.927 & 0.966 & 0.978 \\
\hline
\end{tabular}

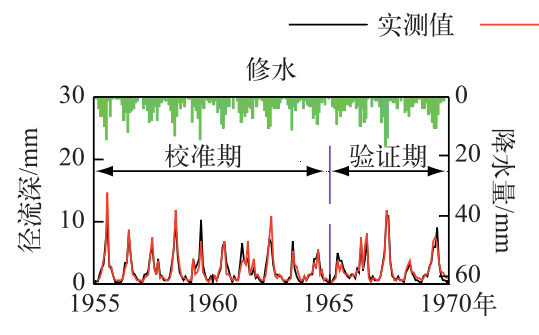

模拟值降水量
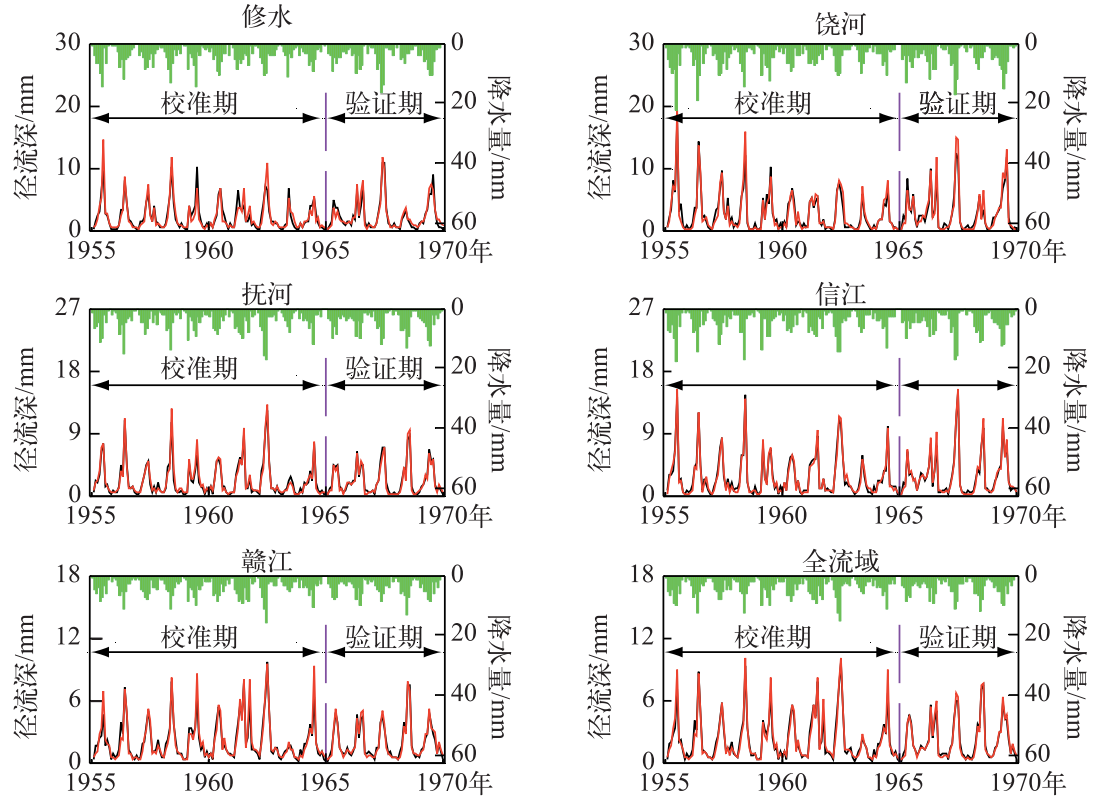

图 3 校准期、验证期模拟与实测月平均径流深对比

Fig.3 Comparison of simulated and observed monthly runoff depth during calibration period and validation period

\section{3 定量分析气候变化与人类活动的影响}

运用校正的多元线性回归模型和 AWBM 模型, 得到影响期 (1970-2009 年) 的模拟径流,并采用公式 (3)、(4) 分离出人类活动与气候变化对径流的影响. 从气候变化影响量曲线图可以看出 (图 4),2种方法 下气候变化影响量差距较小,且不同方法下气候变化对径流的影响方向一致 . 2 种不同方法相互印证,增加 了量化气候变化对径流影响的可信度. 因此, 采用 2 种方法下气候变化影响量 (人类活动影响量) 的均值作 为最终气候变化影响量 (人类活动影响量) (图 4、表 5).

3. 3.1 年尺度下影响量 1955-2009 年“五河”流域降水量均为增加趋势, 潜在蒸发量减少趋势显著( 表 1 ), 使得气候变化对 “五河”年径流量的影响均为增加作用 (表 5), 修水、饶河、抚河、信江、赣江年径流深分 别增加 65、94、112、93 和 $70 \mathrm{~mm}$. “五河” 中气候变化对抚河径流影响最大, 对修水径流影响最小, “五河” 中 抗河流域降水增加趋势最为显著, 修水增加趋势相对最不明显 (表 1), 抚河和修水蒸发量下降趋势在“五 河” 中处于中间水平, 说明径流对降水量变化更为灵敏, 与 Jiang 等 ${ }^{[4]}$ 研究结果一致. 1970s $-1990 \mathrm{~s}$ 气候变化 影响量均为正, 并在 1990s 达到最大(图 4), 影响量在 141.7 316.7 mm/a 之间. 2000 年之后, 各流域气候变 化增加径流作用不明显甚至减少径流, 气候变化影响量在-88.4 26.2 mm/a, 其中抚河、赣江流域气候变化 增加少量径流, 修水、饶河、信江流域气候变化较大幅度减少径流. 就全流域而言, 2000s 气候变化对径流变 化影响甚微,略微减小年径流深.

除修水外,气候变化对 “五河” 径流的影响均大于人类活动的影响, 气候变化对全流域径流增加的贡献 率为 $73.2 \%$. 除抚河外, 人类活动对其它 “四河” 年径流深均有增加作用, 增加 $30.3 \sim 130.9 \mathrm{~mm} / \mathrm{a}$. 相反, 抚 
河受贑抚平原灌区大量引水影响 (引水量占抚河多年平均径流量的 $29.6 \%$ ), 人类活动大幅减少抚河年径流 深为 $-109.2 \mathrm{~mm} / \mathrm{a}$, 在人类活动和气候变化综合影响之下, 抚河年径流量变化甚微, 从而导致贡献率比值较 大. 人类活动对全流域径流量具有增加作用, 对全流域径流增加的贡献率为 $26.8 \% .1990 \mathrm{~s}$ 之前人类活动平 均增加年径流深 $37.7 \mathrm{~mm} / \mathrm{a}$, 而 $2000 \mathrm{~s}$ 增加径流深为 $9.6 \mathrm{~mm} / \mathrm{a}$, 人类活动增加径流作用明显下降. $2000 \mathrm{~s}$ 饶 河、修水流域人类活动影响量从大幅增加径流转变为减少径流, 人类活动对抚河径流的减少量进一步增大.

表 5 气候变化与人类活动对鄱阳湖流域年径流深影响

Tab. 5 Climate and human impact amount for annual runoff in the Poyang Basin

\begin{tabular}{|c|c|c|c|c|c|}
\hline 流域 & $\begin{array}{c}\Delta Q_{\mathrm{tot}}{ }^{\prime} \\
(\mathrm{mm} / \mathrm{a})\end{array}$ & $\begin{array}{l}\Delta Q_{\text {clim }} / \\
(\mathrm{mm} / \mathrm{a})\end{array}$ & $\begin{array}{c}\text { 气候变化贡献率/ } \\
\%\end{array}$ & $\begin{array}{l}\Delta Q_{\mathrm{hum}} / \\
(\mathrm{mm} / \mathrm{a})\end{array}$ & $\begin{array}{c}\text { 人类活动贡献率/ } \\
\%\end{array}$ \\
\hline 修水 & 196 & 65 & 33 & 131 & 67 \\
\hline 饶河 & 157 & 94 & 60 & 63 & 40 \\
\hline 抚河 & 2 & 112 & 50 & -110 & 50 \\
\hline 信江 & 151 & 93 & 61 & 58 & 39 \\
\hline 赣江 & 115 & 70 & 61 & 45 & 39 \\
\hline 全流域 & 110 & 80 & 73 & 30 & 27 \\
\hline
\end{tabular}
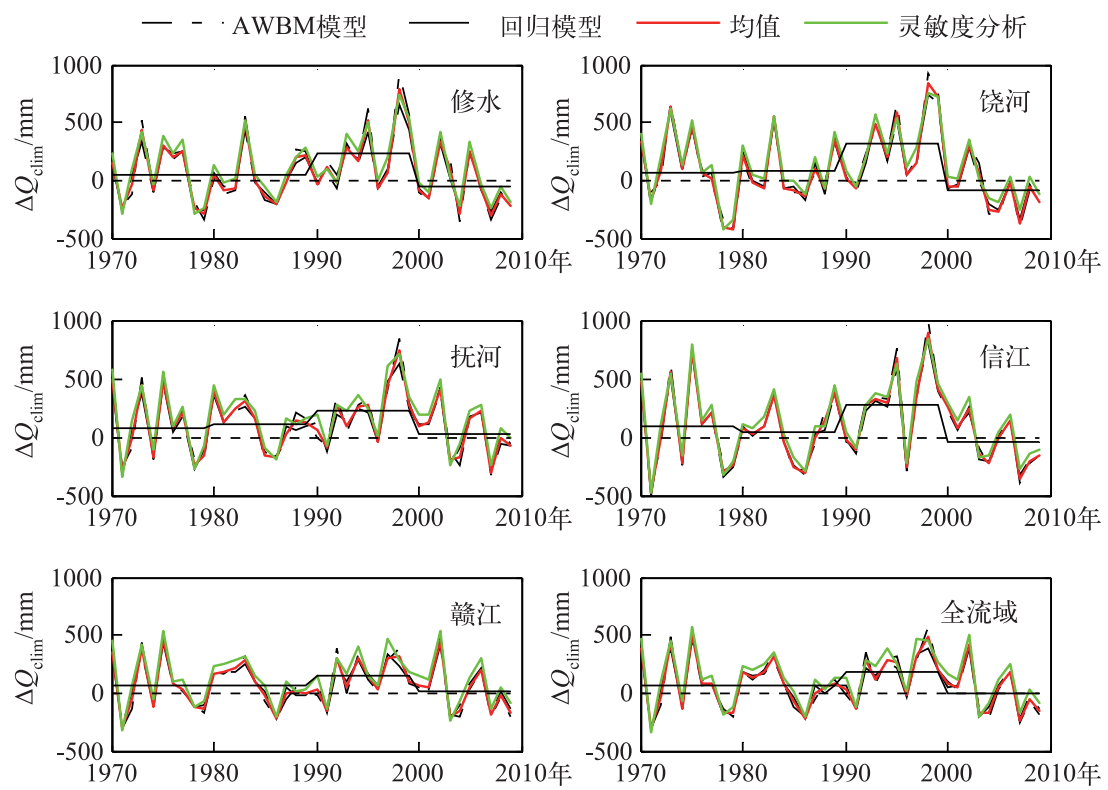

图 4 气候变化对鄱阳湖流域径流深变化的影响

Fig.4 Climate change's impact on runoff depth for Poyang Basin

3. 3.2 季节尺度下影响量 将鄱阳湖流域降水量最大的 4-6 月定义为湿季,而降水量最小的 11 月一次年 1 月定义为干季, 对比分析气候变化与人类活动对干、湿径流变化的影响 (表 6). 干季, 气候变化和人类活动 均增加径流量, 两者对干季全流域径流增加的贡献率分别为 $21.1 \%$ 和 $78.9 \%$. 湿季, 气候变化与人类活动总 体上减少全流域径流量, 两者对全流域径流减少的贡献率分别为 $17.3 \%$ 和 $82.7 \%$. 人类活动对干季径流的 增加作用和对湿季径流量减小作用均占主导地位。

3.3.3 月尺度下影响量 不同月份气候变化和人类活动影响量存在较大差异 (表 7). 2-4 月份, “五河” 年 径流深的变化总量为 $18.3 \sim 55.6 \mathrm{~mm}$, 其中气候变化增加径流深 41.8 71.0 mm, 除修水外, 人类活动对其它 “四河” (饶河、抚河、信江、赣江) 径流量均为减少作用. 5、6 月份, “五河” 径流深减小-32.2 -7.0 mm,其中 
气候变化减小径流深-57.2 - 29.0 mm, 除抚河外, 其它“四河” 人类活动增加径流深 2. 1 25.0 mm. 7-9 月 份, “五河” 径流深变化之和分别为 23.6 129.0 mm, 其中气候变化增加径流深 24. 7 68.1 mm, 除抚河外, 其 它“四河” 人类活动增加径流深 4. 5 60.9 mm. 10 月至次年 1 月, “五河” 径流深变化总量为 25. 1 56.5 mm, 其中气候变化增加径流深分别为 9.3 30.1 mm, 人类活动增加径流深 $15.8 \sim 43.5 \mathrm{~mm}$, 气候变化和人类活动 共同增加径流深, 人类活动影响量大于气候变化影响量.

表 6 气候变化和人类活动对干、湿季径流深变化的影响

Tab. 6 Climate and human impact on runoff depth in dry and wet season

\begin{tabular}{|c|c|c|c|c|c|c|c|}
\hline & & 修水 & 饶河 & 抚河 & 信江 & 赣江 & 全流域 \\
\hline \multirow[t]{3}{*}{ 干季 } & $\Delta Q / \mathrm{mm}$ & 40.3 & 39.1 & 21.3 & 43. 9 & 31.9 & 32.7 \\
\hline & $\Delta Q_{\text {clim }} / \mathrm{mm}$ & 10.5 & 22.1 & 7. 1 & 29.1 & 2. 1 & 6.9 \\
\hline & $\Delta Q_{\text {hum }} / \mathrm{mm}$ & 29.8 & 17.1 & 14. 2 & 14. 8 & 29.8 & 25.9 \\
\hline \multirow[t]{3}{*}{ 湿季 } & $\Delta Q / \mathrm{mm}$ & -20.9 & -21.9 & -53.6 & 23.2 & -0.5 & -5.9 \\
\hline & $\Delta Q_{\text {clim }} / \mathrm{mm}$ & -43.6 & -40.9 & 4.5 & -7.4 & 1.8 & -1.0 \\
\hline & $\Delta Q_{\text {hum }} / \mathrm{mm}$ & 22.7 & 19.0 & -58.0 & 30.6 & -2.3 & -4.9 \\
\hline
\end{tabular}

表 7 气候变化和人类活动对各月径流深的影响

Tab. 7 Climate and human impact on monthly runoff depth

\begin{tabular}{|c|c|c|c|c|c|c|c|c|c|c|c|}
\hline \multirow{2}{*}{ 时间 } & \multicolumn{6}{|c|}{$\Delta Q_{\text {clim }} / \mathrm{mm}$} & \multicolumn{5}{|c|}{$\Delta Q_{\text {hum }} / \mathrm{mm}$} \\
\hline & 修水 & 饶河 & 抚河 & 信江 & 赣江 & 全流域 & 修水 & 饶河 & 抚河 & 信江 & 赣江 \\
\hline 1 月 & 4. 6 & 9.1 & 5.0 & 13. 2 & 3.8 & 5.3 & 7.5 & 0.5 & -0.2 & 0.1 & 6.5 \\
\hline 2 月 & 9.9 & 13.8 & 6.5 & 5.8 & 13.5 & 11.3 & 1.0 & -9.5 & -9.7 & -6.8 & -4.0 \\
\hline 3 月 & 18.4 & 29.9 & 29.3 & 30.8 & 29.4 & 29.4 & 2.8 & -5.1 & -18.8 & -8.7 & -9.5 \\
\hline 4 月 & 13.5 & 3.7 & 35.2 & 29.4 & 30.8 & 30.1 & -2.3 & -1.0 & -24.3 & 0.8 & -4.6 \\
\hline 5 月 & -38.3 & -70.9 & -22.2 & -54.8 & -3.8 & -16.2 & 10.0 & 2. 6 & -19.2 & 5.5 & -1.1 \\
\hline 6 月 & -18.9 & 26.2 & -8.5 & 17. 9 & -25.2 & -14.9 & 15.0 & 17.5 & -14.6 & 24.3 & 3.3 \\
\hline 7 月 & 38.2 & 26.1 & 21.5 & 19.4 & 11.7 & 15.3 & 18.4 & 14.8 & -17.6 & 3.0 & 1. 4 \\
\hline 8 月 & 16. 6 & 22.8 & 27.6 & 18.4 & 13.4 & 16.5 & 19.8 & 2.5 & -15.6 & -0.6 & 6.1 \\
\hline 9 月 & 13.3 & 11.7 & 13. 2 & 2.3 & -0.5 & 2.7 & 22.8 & 15.1 & -5.5 & 12.1 & 11.7 \\
\hline 10 月 & 1.8 & 8.1 & 2. 2 & -5.3 & -1.5 & -0.8 & 13.7 & 9.3 & 1.5 & 13.8 & 12. 2 \\
\hline 11 月 & 6.9 & 13. 0 & 3.3 & 11.4 & -0.1 & 2.4 & 9.6 & 5.4 & 5.5 & 5.9 & 11.2 \\
\hline 12 月 & -1.1 & -0.1 & -1.3 & 4. 5 & -1.6 & -0.8 & 12.7 & 11.1 & 8.9 & 8.9 & 12. 0 \\
\hline
\end{tabular}

\section{4 与灵敏度分析法对比}

灵敏度分析法下气候变化影响量和本文 2 种方法所求气候变化影响量变化模式基本一致,进一步验证 了本文所求结果的正确性 (图 4). 对比 3 种方法下气候变化影响曲线可以看出, 灵敏度分析法下气候变化 影响曲线总体高于其它 2 种方法下气候变化影响曲线. 灵敏度方法下气候变化对 “五河” 径流变化的影响 量明显大于本文方法所求气候变化影响量 (表 8 ).

灵敏度分析法的降水、潜在蒸发灵敏度系数是基于基准期人类活动和气候条件所求得,通过灵敏度分 析法模拟的气候变化影响量实际上是影响期气候条件相对于基准期气候条件和人类活所产生的径流变化, 即气候变化影响量中包含有基准期人类活动的影响 ${ }^{[9]}$. 因此, 若基准期的人类活动增加径流,则所求得气候 变化影响量偏大; 若基准期的人类活动减小径流,则所求得的气候变化影响量偏小. 而长江中下游地区人 类活动对年径流的影响以增加径流为主 ${ }^{[26]}$, 因此灵敏度分析法所求得的气候变化影响量较实际偏大. Ye 等 ${ }^{[7]}$ 以 1960-1970 年为基准期, 采用灵敏度分析法量化气候变化和人类活动对鄱阳湖流域赣江、信江、抚 河 “三河” 径流影响, “三河”气候变化影响量均大于本文模型所求气候变化影响量, 主要由上述原因导致, 
而与本文灵敏度分析法所求结果存在差别的原因可能是,受不同基准期地下水储存量存在差异的影响. 因 此,本文认为灵敏度分析法并不适合在基准期人类活动较为频繁流域上运用.

表 8 灵敏度分析法下气候变化影响量与本文方法所求气候变化影响量的比较 $(\mathrm{mm})$

Tab. 8 Comparison among the results of sensitivity-base method, hydrological models and regression analysis

\begin{tabular}{ccccccc}
\hline 方法 & 修水 & 饶河 & 抚河 & 信江 & 赣江 & 全流域 \\
\hline 水文模型 & 75 & 99 & 118 & 95 & 70 & 84 \\
回归分析 & 55 & 88 & 106 & 91 & 70 & 77 \\
灵敏度分析 & 77 & 104 & 131 & 100 & 91 & 98 \\
\hline
\end{tabular}

\section{5 讨论}

本文利用 AWBM 模型和多元线性回归方法,以 1955-1969 年为基准期,模拟影响期 1970-2009 年径 流 $Q_{\mathrm{sim}} \cdot Q_{\text {sim }}$ 是在影响期气候条件和人类活动的基础上进行模拟校正,并在影响期气候 ( 降水和潜在蒸发) 变 化条件下所得到的径流,故以 $Q_{\mathrm{sim}}$ 减去 $Q_{\mathrm{obs} 1}$ 所得到的气候变化影响量很大程度上排除了基准期的人类活动 影响, 所得气候变化影响量较灵敏度分析法的结果更加合理、精确. 同理, 影响期实测径流 $Q_{\mathrm{obs} 2}$ 是基准期和 影响期的人类活动和气候变化共同作用所产生的结果, 以 $Q_{\mathrm{obs} 2}$ 减去模拟径流 $Q_{\mathrm{sim}}$ 得到的 $\Delta Q_{\mathrm{hum}}$ 为影响期新 增人类活动对径流的影响量.

1956-2000 年降水增加的主要原因是长江以南地区冬季与春季降雨呈增加趋势 ${ }^{[26]}$, 且全年降水也呈 现增加趋势, 特别是 1990s 增加趋势最为显著 ${ }^{[27]}$. 1955-2002 年鄱阳湖潜在蒸发减少趋势显著, 这主要由流 域内太阳净辐射和风速的下降导致 ${ }^{[28]}$. 鄱阳湖流域 1961-2000 年降雨量呈增加趋势, 同时期流域内蒸发 量呈减少趋势 ${ }^{[29]}$, 因此 1970s - 1990s 气候变化增加径流量, 并且在 1990s 增加最为明显. 我国降水量变化 受东亚季风季节性变化影响显著,降水主要集中在夏季, 2000s 夏季降水减少趋势显著 ${ }^{[30]}$, 使该时期年降水 量减少,气候变化影响量明显下降,总体上减少全流域径流量. Zhang 等 $^{[31]}$ 通过对比不同时期水汽通量变 化,认为冬季水汽从自太平洋及南海北上增加导致鄱阳湖流域冬季降水量增加, 与本文气候变化增加干季 径流量基本一致. 研究指出, 夏季水汽向北输送能力减弱, 水汽输送量减少, 使长江流域水汽含量下降, 水 汽上升运动减弱, 导致长江流域夏季降水量显著减少 ${ }^{[32]}$, 从而使气候变化减少湿季径流量. 随着社会经济 的发展和人口的增长, 人类活动对径流变化影响越来越突出. 人类活动可通过河湖围旺、森林改造、建筑用 地和引水工程等方式直接或间接地影响河川径流 ${ }^{[33]}$. 长江中下游地区湖泊面积由 $1950 \mathrm{~s}$ 初的 $17198 \mathrm{~km}^{2}$ 减 少到现在的不足 $6600 \mathrm{~km}^{2}$, 湖泊总面积减少 $61.6 \%{ }^{[34]}$. 近 30 年, 鄱阳湖流域大于 $1.0 \mathrm{~km}^{2}$ 以上的湖泊共消 失 10 个, 其中因围垦而消失的湖泊有 8 个 $^{[35]}$. 由于耕地和林地大量扩张, 盲目围垦侵占了流域内河流、湖 泊大量水域面积, 导致流域内水域面积大幅下降, 流域实际蒸发量减小, 从而增强人类活动对河流年径流量 的增加作用. 在经历 1998 年特大洪水之后,鄱阳湖流域开展了大规模的退田还湖、疏浚河湖等工程,流域内 水域面积逐渐增加. 据统计, 2000-2008 年水域面积增长 $8.0 \%{ }^{[36]}$. 水域面积增加使得流域实际蒸发量增 大, 一定程度上减小河流年径流量. 森林具有保持水土、涵养水源以及增加枯水流量等功能 ${ }^{[24]}$. 鄱阳湖流 域森林覆盖率从 1949 年的 $40.4 \%$ 下降到 1980s 初的 31. 5\%, 该时期森林覆盖率下降导致鄱阳湖流域生态环 境恶化, 水土流失严重, 径流量增多 ${ }^{[37]} .1980 \mathrm{~s} 、 1990 \mathrm{~s}$ 森林覆盖率虽增加迅速, 但以新增人工林和中幼林为 主, 森林结构性矛盾严重削弱了森林生态功能. 进入 21 世纪, 森林覆盖率提高到 $60.1 \%$, 原有中幼林已成 林,森林保持水土、涵养水分功能得到充分发挥,一定程度上起到了消减径流的作用.

1990s 以前, 森林破坏、水域面积减少及建筑用地的增加, 使流域蒸发量减小、降水下渗增加, 人类活动 增加流域径流量. 2000 年之后, 森林植被得以恢复, 水域面积增加,一定程度上减小河川径流; 同时, 该时期 江西省城市化进程的加快, 流域内建筑用地迅速增加 ${ }^{[38]}$, 降水下渗及蒸发减少, 径流增加, 在这些因素的综 合作用下, 该时期人类活动对径流的影响甚微. 引水灌溉减小河川径流, 这种影响在抚河最为明显, 江西省 灌溉面积最大的赣抚平原灌渠平均每年向抚河引水 $37.6 \times 10^{8} \mathrm{~m}^{3}$, 占抚河多年平均径流量的 $29.6 \%$. 大规模 引水使年径流大幅减小, 直接导致抚河流域人类活动对径流的影响模式与其它 “四河” 流域不同. 引水灌溉 
对其它” 四河” 径流的影响主要体现在雨季到来前的 2-5 月. 人类活动对鄱阳湖流域径流变化影响复杂, 不同类型人类活动相互叠加或相互削弱, 径流量在不同类型人类活动共同作用下产生变化. 本文分析各种 人类活动分别对鄱阳湖流域径流的影响,但并未尝试分离不同类型人类活动对径流的具体影响量.

\section{6 结论}

以 1955-1969 年为基准期,采用多元线性回归方法和 AWBM 模型, 定量分析气候变化与人类活动对鄱 阳湖流域径流的影响。趋势分析表明, “五河”流域年降水量均呈增加趋势, 年蒸发量下降趋势显著,除抚河 外其它 “四河” 年径流量均呈显著增加趋势. 多元线性回归模型解释变量选择上,通过对比不同解释变量下 校正决定系数, 得出加人蒸发及上月降水量两个解释变量的三元降水径流回归模型回归效果最佳. AWBM 模型模拟结果的 $N A S H$ 系数均在 0.842 以上,较多元线性回归模拟效果更佳. 鉴于 2 种方法下气候变化和 人类活动影响量变化模式非常相似, 可以认为 2 种方法均适合定量区分气候变化与人类活动对径流的影 响, 采用 2 种方法的平均值相对单一方法所求结果更为可靠. 与常用的灵敏度分析方法对比, 其结果与本文 所求气候变化影响量变化模式基本一致,进一步验证了本文所求结果的可靠性. 但灵敏度方法无法排除基 准期的人类活动的影响,在基准期的人类活动增加径流的情况下,所求气候变化影响量偏大.

气候变化和人类活动总体上增加鄱阳湖流域径流量, 两者对全流域径流增加的贡献率分别为 $73 \%$ 和 $27 \%$. 气候变化对 “五河”径流量均有增加作用, 人类活动增加除抚河以外的其它 “四河” 径流量, 抚河径流 量受大量引水灌溉影响, 年径流量呈减少趋势. 气候变化和人类活动对径流变化影响在不同时间尺度上存 在较大差异. 年尺度上, $1970 \mathrm{~s}-1990 \mathrm{~s}$ 人类活动和气候变化均较大幅度增加径流量. $2000 \mathrm{~s}$ 气候变化一定程 度上减少全流域年径流量, 该时期人类活动对径流的增加量影响也相对较小. 季节尺度上,气候变化和人 类活动对流域内干季径流量均有增加作用, 而对湿季全流域径流量有减少作用. 人类活动影响量在干、湿 季均占主导地位, 对干季径流量增加和湿季径流量减少的贡献率分别为 $78.9 \% 、 82.7 \%$. 气候变化和人类活 动对各月径流量的影响差别较大, 气候变化是 5-6 月份径流减小的主要原因, 人类活动减小雨季到来前的 2-5 月径流量. 以不同时间尺度定量区分气候变化和人类活动对鄱阳湖流域径流变化的影响,可为区域水 旱灾害治理和水资源规划管理提供科学依据和重要参考.

\section{7 参考文献}

[ 1 ] Zhang Q, Li J, Chen YD et al. Observed changes of temperature extremes during 1960 - 2005 in China: natural or humaninduced variations? Theoretical and Applied Climatology, 2011, 106(3/4) : 417-431.

[ 2 ] Xiao M, Zhang Q, Singh VP. Influences of ENSO, NAO, IOD and PDO on seasonal precipitation regimes in the Yangtze River basin, China. International Journal of Climatology, 2014, 35: 3556-3567.

[ 3 ] Bao Z, Zhang J, Wang G et al. Attribution for decreasing streamflow of the Haihe River basin, northern China: Climate variability or human activities? Journal of Hydrology, 2012, 460: 117-129.

[ 4 ] Jiang S, Ren L, Yong B et al. Quantifying the effects of climate variability and human activities on runoff from the Laohahe basin in northern China using three different methods. Hydrological Processes, 2011, 25(16) : 2492-2505.

[ 5 ] Miao C, Ni J, Borthwick AGL et al. A preliminary estimate of human and natural contributions to the changes in water discharge and sediment load in the Yellow River. Global and Planetary Change, 2011, 76(3) : 196-205.

[6] Ahn KH, Merwade V. Quantifying the relative impact of climate and human activities on streamflow. Journal of Hydrology, 2014, 515: 257-266.

[ 7 ] Ye X, Zhang Q, Liu J et al. Distinguishing the relative impacts of climate change and human activities on variation of streamflow in the Poyang Lake catchment, China. Journal of Hydrology, 2013, 494: 83-95.

[ 8 ] 夏智宏, 刘 敏, 王 苗等. 1990s 以来气候变化和人类活动对洪湖流域径流影响的定量辨识. 湖泊科学, 2014, 26(4) : 515-521. DOI 10. 18307/2014. 0404.

[ 9 ] Wang X. Advances in separating effects of climate variability and human activity on stream discharge: An overview. Advances in Water Resources, 2014, 71: 209-218.

[10] Zeng S, Xia J, Du H. Separating the effects of climate change and human activities on runoff over different time scales in the Zhang River basin. Stochastic Environmental Research and Risk Assessment, 2014, 28(2) : 401-413. 
[11] Guo H, Hu Q, Jiang T. Annual and seasonal streamflow responses to climate and land-cover changes in the Lake Poyang Basin, China. Journal of Hydrology, 2008, 355: 106-122.

[12] 田 鹏. 气候与土地利用变化对径流的影响研究 [学位论文]. 杨凌: 西北农林科技大学, 2012.

[13] 邓晓宇, 张 强, 孙 鹏等. 气候变化和人类活动对信江流域径流影响模拟. 热带地理, 2014, (3): 293-301.

[14] 谢 军, 黄智权, 杨巧言. 江西省自然地理志. 北京: 方志出版社, 2003: 213-219.

[15] 闵 骞. 鄱阳湖水位变化规律的研究. 湖泊科学, 1995, 7 (3) : 281-288. DOI 10. 18307/1995. 0312.

[16] Allen RG, Pereira LS, Raes D et al. Crop evapotranspiration-Guidelines for computing crop water requirements-FAO Irrigation and drainage paper 56. FAO, Rome, 1998, 300: 6541.

[17] Sen PK. Estimates of the regression coefficient based on Kendall's tau. Journal of the American Statistical Association, 1968, 63(324) : 1379-1389.

[18] Yue S, Pilon P, Phinney B et al. The influence of autocorrelation on the ability to detect trend in hydrological series. Hydrological Processes, 2002, 16(9): 1807-1829.

［19］孙 鹏，张 强，陈晓宏等. 鄱阳湖流域水沙时空演变特征及其机理. 地理学报，2010，(7)：828-840.

[20] Boughton W. The Australian water balance model. Environmental Modelling \& Software, 2004, 19(10) : 943-956.

[21] Theil H, Nagar AL. Testing the independence of regression disturbances. Journal of the American Statistical Association, 1961, 56(296) : 793-806.

[22] Harel 0 . The estimation of R2 and adjusted R2 in incomplete data sets using multiple imputation. Journal of Applied Statistics, 2009, 36(10): 1109-1118.

[23] Boughton W, Chiew F. Estimating runoff in ungauged catchments from rainfall, PET and the AWBM model. Environmental Modelling \& Software, 2007, 22(4): 476-487.

[24] 刘剑宇, 张 强, 顾西辉. 水文变异条件下鄱阳湖流域生态流量研究. 生态学报, 2015, (16) : 5477-5485.

[25] Moriasi DN, Arnold JG, Van Liew MW et al. Model evaluation guidelines for systematic quantification of accuracy in watershed simulations. Transactions of the ASABE, 2007, 50(3) : 885-900.

[26] 张 强, 孙 鹏, 陈 喜等. 1956-2000 年中国地表水资源状况: 变化特征、成因及影响. 地理科学, 2011, 12: 1430-1436.

[27] 王 英, 曹明奎, 陶 波等. 全球气候变化背景下中国降水量空间格局的变化特征. 地理研究, 2006, (6): 1031-1040, 1148 .

[28] Wang Y, Jiang T, Bothe O. Changes of pan evaporation and reference evapotranspiration in the Yangtze River basin. Theoretical and Applied Climatology, 2007, 90(1/2): 13-23.

[29］郭 华, 姜 䑣, 王国杰等. 1961-2003 年间鄱阳湖流域气候变化趋势及突变分析. 湖泊科学, 2006, 18(5): 443-451. DOI 10. 18307/2006. 0501.

[30] Zhang Q, Xu CY, Jiang T. Possible influence of ENSO on annual maximum streamflow of the Yangtze River, China. Journal of Hydrology, 2007, 333(2) : 265-274.

[31] Zhang Q, Liu Y, Yang G et al. Precipitation and hydrological variations and related associations with large-scale circulation in the Lake Poyang Basin, China. Hydrological Processes, 2011, 25(5) : 740-751.

[32] Zhu Y, Wang H, Zhou W et al. Recent changes in the summer precipitation pattern in East China and the background circulation. Climate Dynamics, 2011, 36(7/8) : 1463-1473.

[33] Zhang Q, Chen G, Su B et al. Periodicity of sediment load and runoff in the Yangtze River basin and possible impacts of climatic changes and human activities. Hydrological Sciences Journal, 2008, 53(2) : 457-465.

[34］吴瑞金.我国湖泊资源环境现状与对策。中国科学院院刊, 2001，(3)：176-181.

[35] 马荣华, 杨桂山, 段洪涛等。中国湖泊的数量、面积与空间分布.中国科学: 地球科学, 2011, (3): 394-401.

[36] Liu H, Xia H, Zhou B. Land use information extraction and spatio-temporal variation analysis of Lake Poyang Basin based on remote sensing. In: Eighth International Symposium on Multispectral Image Processing and Pattern Recognition. International Society for Optics and Photonics, 2013: 892113.

[37］刘 健, 张 奇, 许崇育等. 近 50 年鄱阳湖流域径流变化特征研究. 热带地理, 2009, (3): 213-218, 224.

[38] 张起明, 胡 梅, 齐述华等. 1980-2005 年江西省土地利用变化政策因素驱动力分析. 江西科学, 2011, (5): 597-602. 